\title{
Los nobles contra su rey. Argumentos y motivaciones de la insubordinación nobiliaria de 1272-1273
}

\author{
Julio Escalona \\ Departamento de Historia medieval, \\ Instituto de Historia, CSIC, Madrid \\ SIREM, GDR 2378, CNRS
}

\begin{abstract}
RÉSUMÉ
À travers l'analyse du passage de la Chronique d'Alphonse $\mathrm{X}$ consacré aux événements des années 1272-1273, l'on tente une approche de la pensée politique de la noblesse castillane du XIII siècle telle que ces événements la reflètent. L'on suggère: a) que le véritable mobile, non déclaré, de la révolte a pu être l'opposition nobiliaire - principalement des Lara - aux ambitions impériales d'Alphonse X; b) que l'étude approfondie des revendications nobiliaires ne révèle pas seulement des ambitions et des intérêts particuliers, mais encore l'existence d'idées sur le royaume, la société et le rôle de la noblesse dans celle-ci qui se heurtent aux initiatives monarchiques des décennies antérieures.
\end{abstract}

\section{Resumen}

A través de una sección específica de la Crónica de Alfonso $X$, se realiza un acercamiento al pensamiento político de la nobleza castellana del siglo XIII, tal y como se refleja en los acontecimientos de 1272-1273. Se sugiere : a) que el auténtico móvil no declarado de la revuelta pudo ser la oposición nobilaria - principalmente de los Lara - a las ambiciones imperiales de Alfonso X; b) que el estudio en profundidad de las reivindicaciones nobiliarias no sólo revela ambiciones e interes particularistas, sino también la existencia de concepciones sobre el reino, la sociedad y el papel de la nobleza en la misma que entran en colisión con las iniciativas articuladas desde la monarquía en los decenios precedentes. 
Es difícil considerar la cuestión del pensamiento político nobiliario sin que, al momento, venga a la mente la antagonía entre nobleza y monarquía. Este antinomio - elevado a veces a la categoría de auténtica clave interpretativa - reaparece una y otra vez en las explicaciones de los historiadores sobre las estructuras y las prácticas políticas medievales, acentuándose más cuanto más nos acercamos a las etapas finales del medievo. Pero, ¿ son necesariamente nobleza y monarquía términos antitéticos en intereses y objetivos? ¿ lo son en cuanto a su ideario político?

Aquí hay un evidente escollo teórico, puesto que lo que se confronta no son, obviamente, elementos homogéneos ${ }^{1}$. La nobleza es la clase social dominante en el sistema feudal; la monarquía, en cambio - mucho más allá de la personalidad individual del rey - es en la plena Edad Media un aparato organizacional en acelerado crecimiento, germen de las estructuras formales que acabarán por componer las sofisticadas maquinarias estatales bajomedievales. Una estructura organizacional como esta no puede constituirse ni operar al margen de la clase dominante del sistema político en el que surge. Dicho de otra manera, la totalidad del sistema político medieval - como bien saben los especialistas del período - está atravesada por los tentáculos de la nobleza, en cuanto a presencia, influencia, prácticas y, muy especialmente, cultura e ideario político. Esto, que parece demasiado obvio para necesitar ser escrito, debería, sin embargo, servir para subrayar la dificultad de deslindar un pensamiento político nobiliario y otro de la monarquía, a menos que caigamos en la tentación de la historiografía tradicional de atribuir a la monarquía todos los movimientos que, en sentido teleológico, conducen hacia el « Estado moderno », cargando a la nobleza con la acusación de actuar contra el Estado, o bien de instrumentalizarlo, movida sólo por egoístas intereses personales o de grupo. Interrelación, que no identidad.

1. Agradezco los comentarios y sugerencias de Isabel Alfonso, Carlos Estepa y Cristina Jular. Agradezco especialmente a C. Estepa haberme permitido utilizar el manuscrito de su monumental libro Las behetrías castellanas, en curso de publicación. Ver un planteamiento crítico, referido en este caso a la baja nobleza, en Reyna PASTOR BAÑOS, Carlos ESTEPA DÍEZ, Isabel ALFONSO ANTÓN, Julio ESCALONA MONGE, Cristina JULAR PÉREZ-ALFARO, Esther PASCUA ECHEGARAY y Pablo SÁNCHEZ LEÓN, « Baja Nobleza : aproximación a la historiografía europea y propuestas para una investigación ", Historia social, 20, 1994, p. 23-45. 
No es posible, desde luego, comprender el pensamiento político de las monarquías plenomedievales sin considerar la omnipresencia de elementos clave de la ideología nobiliaria. Pero entender - como se hace a veces - el Estado como mera emanación de la clase dominante y el pensamiento político promovido desde la Monarquía como una forma de acción social de los señores feudales tampoco resuelve la papeleta.

¿Cómo, pues, plantear la existencia de un pensamiento político de la nobleza diferenciado del de una monarquía tan directamente imbricada con la clase nobiliaria? Para el ámbito castellano-leonés anterior al siglo XIV no es fácil abordar estas cuestiones sobre un bloque de material heurístico suficientemente rico y adecuado. Las más de las veces, los historiadores se ven obligados a trabajar « en negativo », a intentar imaginar el ideario político de la nobleza a través del estudio del discurso regio, el único que llega en cantidad suficiente para permitir un análisis sutil y pormenorizado. Sin duda aquí juega un cierto papel el hecho de que estos materiales, sobre todo los de carácter legal o normativo, tienen un atractivo intrínseco indudable. También es posible que haya que contar con el hecho de que, al aceptarse tácitamente la relación antinómica nobleza-monarquía, se asuma inconscientemente que el discurso regio retrata por negación el de la nobleza.

Más allá de los textos normativos, esta limitación puede ser superada por medio del estudio de conflictos reales que enfrenten a nobleza y monarquía, en los cuales se puedan ver expresadas posturas enfrentadas y discursos alternativos. El problema es disponer de fuentes que permitan sondear las estrategias y las prácticas de lucha de la nobleza y, a partir de ellas, deducir el ideario que hay detrás. Este trabajo pretender ser una modesta exploración en este sentido, a través de un episodio concreto, no exento de problemas: la revuelta de los nobles castellanos contra Alfonso X en 1272-1273, a través del extenso relato que proporciona la Crónica de Alfonso $X^{2}$.

\section{LOS AGONTEGIMIENTOS Y EL MATERIAL TEXTUAL}

El conflicto que centrará mi atención es, muy resumidamente, el que sigue : a comienzos de 1272 el infante don Felipe, hermano del rey, y los jefes de los tres principales linajes de ricoshombres: Lara, Haro y Castro, se unieron contra Alfonso X enarbolando una amplia serie de reivindicaciones, que comentaré más adelante. Las concesiones ofrecidas

2. Para todo mi análisis de este material textual, es fundamental tener en cuenta los puntos de vista expresados en Isabel ALFONSO ANTÓN, «Desheredamiento y desafuero, o la pretendida justificación de una revuelta nobiliaria », en este mismo volumen, p. 99-129. 
por Alfonso X meses después en las cortes de Burgos no les hicieron desistir, y determinaron desnaturarse del reino, exiliándose junto al rey de Granada. La situación se resolvió al año siguiente, gracias a una mezcla de concesiones y amenazas que regias persuadieron a los nobles para volver al servicio del monarca ${ }^{3}$. No obstante, muchos de los temas suscitados rebrotaron años después con ocasión de la revuelta del infante don Sancho.

La narración más próxima a los hechos, la Crónica de los reyes de Castilla de Jofré de Loaysa, despacha este episodio de forma más bien lacónica :

Postmodum autem discordiam magnam habuit cum quampluribus baronibus terre sue, adeo quod mille ducenti et ultra de baronibus, infancionibus et nobilibus ipsius ad regem Granate propterea accesserunt et ibi per tempus aliquod permanserunt, quousque rex ipse clemens ad precum instanciam infantis Fernandi filii regis eiusdem ac nobilis et reverendi patris Sancii, filii regis Aragonum et tunc archiepiscopi toletani, pepercit eisdem et illuc misit pro ipsis et ipsi libenter ad eius graciam redierunt. Inter quos principaliores fuerunt domnibus Philippus germanus regis ipsius, domnus Nunio cum domno Johanne Nunionis et domno Nunione filiis eius, dompnus Lupus Didaci dominus Vizcaye et alii multi barones, infanciones et nobiles ${ }^{4}$.

Sin embargo, la Crónica de Alfonso $X$ proporciona un relato mucho más vivo y detallado, constituyendo la fuente primordial sobre la insubordinación, en combinación con el rico material documental conservado de tiempos del rey Sabio $^{5}$. Sobre esta fuente voy a basar mi análisis.

Consideremos este material textual. Se suele atribuir la redacción de la Crónica de Alfonso X a Fernán Sánchez de Valladolid, canciller del sello de la poridad de Alfonso XI, quien habría recibido del rey el encargo de continuar la Estoria de España, interrumpida en el reinado de Fernando III, con la narración de los reinados de Alfonso X, Sancho IV, Fernando IV y Alfonso XI. El texto es, por tanto, una obra muy posterior a los acontecimientos que narra, concebida con una clara visión de

3. Para una exposición de conjunto de los acontecimientos, ver Manuel GONZÁLEZ JIMÉNEZ, Alfonso X, Palencia, 1993, p. 95-106. La síntesis más difundida, debida a Antonio BALLESTEROS BERETTA, Alfonso X el Sabio, Barcelona, 1984 ( $2^{\mathrm{a}}$ ed.) presenta graves problemas de cronología, derivados de los propios errores de datación de la Crónica de Alfonso X. Deben tenerse en cuenta las abundantes correcciones establecidas por Manuel González Jiménez, a través del cotejo de la crónica con los documentos y con el itinerario regio, en su nueva edición del texto [Manuel GONZÁLEZ JIMÉNEZ (ed.), Crónica de Alfonso X, Murcia, 1998]. 4. Antonio GARCíA MARTÍNEZ (ed. y trad.), Jofré de Loaysa. Crónica de los Reyes de Castilla, Murcia, 1982, p. 86.

5. M. GONZÁLEZ JIMÉNEZ, Crónica de Alfonso X. Aunque en los últimos decenios ha aumentado notablemente el corpus de documentos del reinado de Alfonso X publicados, para una visión general sobre las fuentes, sigue siendo útil A. BALLESTEROS BERETTA, Alfonso X el Sabio. 
influir tanto en la interpretación del pasado como en la comprensión del presente $^{6}$. Mirando, pues, hacia atrás desde la perspectiva del tiempo de Alfonso XI, es claro que sobre el trabajo del cronista pesaron unos condicionantes y unos presupuestos que deben ser tenidos muy en cuenta. El tratamiento de la figura de Alfonso X en la crónica parte de la necesidad de justificar la línea dinástica reinante presentando al rey como un mal gobernante y la rebelión de Sancho IV contra su padre como plenamente justificada, pero al mismo tiempo carga con la contradicción de tener que sustentar la idea de un rey fuerte frente a la nobleza. La cuestión de la revuelta nobiliaria, por lo tanto, tiene una significación enorme tanto en el contexto del reinado de Alfonso X como en el de Alfonso XI, pero se inscribe en coordenadas históricas diferentes para uno y otro ${ }^{7}$.

Centrándose en el relato de los hechos de 1272-1273, ha sido destacado varias veces que los treinta y ocho capítulos de la crónica - del XX al LVIII - que narran este episodio constituyen un bloque con personalidad propia en el conjunto de la obra. Se piensa que Fernán Sánchez de Valladolid no redactó directamente esta sección, sino que incorporó - no sin retoques - un texto preexistente, redactado en la corte de Alfonso X en el contexto de la rebelión del infante Sancho (1282-1284), quizá formando parte del material recopilado para formar parte de la Estoria de España, en la variante de la misma que se viene denominando Versión crítica, y que refleja el giro de los acontecimientos después de 1275, principalmente con el fracaso del fecho del Imperio ${ }^{8}$. Este relato habría sido compuesto no sólo en favor de la causa del rey, sino también para servir en la práctica como instrumento contra los sublevados, ya que los hechos de 1272-1273 adquirirían una gran actualidad ante la nueva situación.

Para su composición, el anónimo autor parece haber tenido acceso al material documental de los archivos regios ${ }^{9}$, así como a relatos orales de personas implicadas en los hechos, como revelan las detalladas descrip-

6. Sobre el ánimo y los métodos de trabajo de Sánchez de Valladolid, ver Fernando GÓMEZ REDONDO, «De la crónica general a la real. Transformaciones ideológicas en Crónica de tres reyes ", in: Georges MARTIN (dir.), La historia alfonsí : el modelo y sus destinos (siglos XIII-XIV), Madrid, 2000, p. 95-123, esp. p. 102 sq.

7. Sobre los condicionantes de redacción y su contexto político, ver la discusión de Isabel ALFONSO, «Desheredamiento y desafuero... », en este mismo volumen, y también el estudio introductorio a la edición de la Crónica por González Jiménez, así como Manuel CALDERÓN CALDERÓN, « La imagen del rey en la Crónica de Alfonso X», Boletín de la Real Academia de la historia, 197 (2), 2000, p. 255-266, y Fernando GÓMEZ REDONDO, Historia de la prosa medieval castellana, 1. La creación del discurso prosístico : el entramado cortesano, Madrid, 1998, p. 965-968 y 971 976. Para una descripción detallada del contenido de la crónica, ver la edición de González Jiménez y los dos estudios de Gómez Redondo citados.

8. Inés FERNÁNDEZ-ORDÓÑEZ (ed.), Versión crítica de la " Estoria de España ». Estudio y edición desde Pelayo hasta Ordoño II, Madrid, 1993.

9. M. GONZÁLEZ JIMÉNEZ, Crónica de Alfonso $X$, p. vii-xlvi, esp. p. xxxi-xxxvi; F. GÓMEZ REDONDO, Historia de la prosa..., p. 975-976. 
ciones de confrontaciones esencialmente verbales, hasta ahora insuficientemente valoradas. Pero tanto documentos escritos como testimonios orales han pasado claramente por un complejo proceso de elaboración, basado en seleccionar y descartar, extractar y comentar los materiales, y en ordenarlos inteligentemente para que los propios hechos relatados carguen con la responsabilidad del mensaje inserto en la narración. En último término - y frente a la extendida opinión de que el texto es poco menos que una retahíla de documentación original transcrita o extractada -, no cabe desdeñar que una buena parte de este material sea básicamente una elaboración narrativa que reproduce el discurso oral o epistolar por razones de estilo y credibilidad ${ }^{10}$.

La inserción de un texto diferente del resto de la crónica viene marcada, por una parte, por la frecuencia con que el texto alude a un escripto que parece seguir; y, por otra, porque todo el bloque formado por los capítulos XX-LVIII acusa una gran coherencia interna - temática, estilística y en cuanto a la riqueza y precisión de los detalles - que contrasta con fuerza con las secciones antecedente y subsequente. Pero se pueden señalar otras razones más profundas que apuntan en la misma dirección $^{11}$, derivadas de analizar la forma en que el relato de la insubordinación nobiliaria se integra en el discurso general de la crónica. Prestemos atención a los capítulos que anteceden al bloque que nos interesa: tras una breve introducción, la crónica se inicia con una sucesión de episodios relativamente inconexos, que quizá existiesen anteriormente de forma separada, como historias o anécdotas elogiosas de la figura de Alfonso $\mathrm{X}^{12}$. Fernando Gómez Redondo ha sugerido que tanto estos pasajes como el extenso relato de la revuelta formarían parte de los materiales compilados, pero aún sin interconectar, destinados a formar parte un día de la narración del reinado de Alfonso X dentro de la Estoria de España; parte de ellos habría dado lugar a la que él denomina Estoria del rey don Alfons $0^{13}$. Es un conjunto heterogéneo, en cualquier caso; mientras algunos elementos parecen generados para apoyar y rematar la ambición imperial del rey, como parece haber sido el espíritu inicial que animó la redacción de la Estoria de España en su conjunto ${ }^{14}$, otros, como el bloque

10. Ver al respecto ALFONSO, «Desheredamiento y desafuero... ».

11. M. GONZÁLEZ JIMÉNEZ, Crónica de Alfonso $X$, p. xvii $s q$.

12. Las escenas, que constituyen unidades narrativas casi inconexas, se suceden en desorden cronológico en el texto. Si, como tales anécdotas, hubieran existido previamente para ser luego reunidas - y manipuladas - por Sánchez de Valladolid, ello explicaría la aparición de algunas de ellas en la Historia dialogada (ver F. GÓMEZ REDONDO, op. cit., p. 973-975 y la comparación tabular presentada por M. GONZÁLEZ JIMÉNEZ, Crónica de Alfonso X, p. xxiii-xxx).

13. F. GÓMEZ-REDONDO, « De la crónica general a la real... », p. 116.

14. Inés FERNÁNDEZ-ORDÓÑEZ, Las « Estorias» de Alfonso X el Sabio, Madrid, 1992. 
que nos interesa, pertenecen claramente a los tiempos posteriores al fracaso del fecho del Imperio.

Sánchez de Valladolid hace de ellos un uso que es todo menos inocente. Si estos relatos estaban suficientemente difundidos en los círculos cortesanos y eran conocidos por su potencial audiencia, no cabía cambiar o desvirtuar radicalmente su contenido, de forma que el cronista recurre a expedientes más sutiles. Por ejemplo, en el capítulo XVII, la emperatriz de Constantinopla llega a Castilla tras recorrer Europa reclamando ayuda para liberar a su esposo. El hecho de que Alfonso X pague el rescate que otros soberanos se habían negado a satisfacer realza la calidad « imperial » del rey por analogía con el Imperio latino de Oriente. Sin embargo, en la crónica, este elogioso pasaje se cierra con una frase que vuelve hábilmente la historia en contra del monarca :

E todos quantos lo oyeron presçiauan mucho este rey de Castilla. E sallió este enperador de catiuo e pedricaua la bondat e nobleza del rey don Alfonso. Et sonada esta boz por todas las tierras acaesçió que murió el enperador de Alemanna e ayuntáronse los esleedores para acordar a quién fiziesen enperador, e algunos dellos esleyeron por enperador en discordia al rey don Alfonso e acordaron de enbiar por él et que viniese a resçibir el inperio. E como quier que esto fue grant su buena fama del rey don Alfonso en las otras tierras, pero esto e otras cosas atales que este rey fizo troxieron gran enpobreçimiento en los regnos de Castilla e de León.

De esta manera, una narración que podría haber servido originalmente para subrayar las «virtudes » de Alfonso X y su idoneidad como candidato imperial, es ligeramente retocada, lo justo para volverla en contra del rey, subrayando su prodigalidad ${ }^{15}$, idea que se retoma en el capítulo siguiente al considerar los perjuicios sobrevenidos a Castilla por el proyecto imperial (los servicios extraordinarios que el rey exige para dar cumplimiento al fecho del Imperio).

Más importante es el episodio del tributo de Portugal. El capítulo XIX - con el antecedente del capítulo VII para el intervencionismo sobre Portugal - narra cómo don Dionís, hijo del rey de Portugal y nieto de Alfonso X, con ocasión de ser armado caballero por éste, solicita que se quite a Portugal la obligación debida a León de acudir a cortes y de aportar tropas de a caballo a la guerra contra los moros. El rey se lo otorga por magnanimidad, pero lo hace contra el consejo de sus magnates, especialmente de Nuño de Lara, quien argumenta contra el uso por el rey de los bienes del reino para hacer frente a sus compromisos personales :

E don Nunno por esto levantóse en pie e dixo : «Sennor, yo deteníame de vos dar mi consejo sobre esto porque de buena razón es que los infantes vuestros

15. F. GÓMEZ REDONDO, op. cit., p. 973-975. 
hermanos que están aquí e don Lope Díaz de Haro e don Esteuan uos dixesen primeramente lo que más es vuestro serviçio. Pero, sennor, pues vos tenedes por bien que vos responda sobre esto, fazerlo he. Sennor, que vos fagades mucha honra e mucho bien al infante don Deonís vuestro nieto dándole de vuestro aver lo que fuere la vuestra merçed et de vuestras donas e muchos cauallos, es muy gran derecho e deuédeslo fazer por el debdo que convusco ha et porque veno ser vuestro cavallero, et avn sy le cunpliere vuestra ayuda en qualquier cosa que sea menester sodes tenudo de fazer por él e por su honra asy commo por vno de vuestros fijos. Mas, sennor, que vos tiredes de la corona de vuestros regnos el tributo quel rey de portugal e su regno son tenudos de vbos fazer, yo, sennor, nunca vos lo consejaré [...]. »

Se trata claramente de un episodio ficticio, de claras resonancias épi$\operatorname{cas}^{16}$, pero que tienen la virtud de proporcionar al cronista el referente idóneo para introducir la narración sobre la revuelta nobiliaria. Gracias a este recurso, el relato de la conjura (cap. Xx) se abre, en lugar de contra un fondo neutro, sobre el escenario de una ofensa personal del rey a Nuño de Lara y, lo que es más, un enfrentamiento en el que la « razón de Estado » está claramente del lado del noble, por contraste con un rey endiosado, que posterga los intereses de su reino en su afán de mostrarse magnánimo y espléndido ante los demás reyes. El tributo de Portugal tiene también la función de proporcionar el detonante inmediato para una revuelta que, como se verá, carece de él en gran medida : el capítulo XIX finaliza con un imaginario encuentro - la verdadera confabulación parece haberse tejido en 1272 en Lerma - entre el infante Felipe y los cabezas de los linajes de Lara, Haro y Castro, en el que los cuatro acordaron oponerse al rey. De esta manera, el cronista consigue presentar la decisión de los nobles como reacción inmediata a lo ocurrido con don Dionís y el tributo. Pero si éste hubiese sido el casus belli de los rebeldes, es llamativo que en el ulterior desarrollo de los hechos no vuelva nunca a tratarse la cuestión. Parece obvio que el episodio del tributo de Portugal era ajeno al anónimo escripto y su inserción obedece a la pluma de Sánchez de Valladolid.

Esto permite apreciar la estrategia del cronista, quien, antes de dar paso a la narración de la revuelta - donde los nobles aparecen como mezquinos conspiradores movidos por intereses rastreros - coloca un episodio que predispone al lector en contra del rey, dando así un margen de legitimidad a las reclamaciones de los magnates. Se trata de un equilibrio delicado, en el que saltan a la luz las contradicciones que pesan

16. En el «tributo » portugués - consistente en acudir a las convocatorias de cortes y ceder tropas para la guerra contra los moros - resuenan ecos del Poema de Fernán González, por entonces en pleno auge de popularidad. Compárese con el nada literario tributo de 300000 maravedís anuales que se asigna al rey de Granada en el cap. LVIII. Ver nota siguiente. 
sobre el cronista. Por una parte, el escripto utilizado para los capítulos XXLVIII se esforzaba por deslegitimar las demandas de los magnates y por mostrar al rey luchando contra las ambiciones de sus nobles, proporcionando con ello un valioso muestrario de actitudes y conductas regias, de gran valor en el contexto histórico de la crónica. Pero, por otra parte, era necesario cargar sobre Alfonso X la responsabilidad de un descontento nobiliario y unas exigencias que, en último término, estaban también en la base de la revuelta liderada por el infante Don Sancho, punto de arranque de la línea dinástica de Alfonso XI; ante esta necesidad, los capítulos previos tienen la función de introducir elementos legitimadores de la oposición a Alfonso X, entre ellos, la imagen de un rey soberbio y pródigo, más interesado en su fama personal que en el bien de su reino.

Como se ve, la relación entre el relato de la revuelta nobiliaria y el conjunto de la crónica es compleja, y no sólo porque se trate de una mezcla de materiales, sino, sobre todo, porque hay un intrincado cruce de condicionantes e intencionalidades que gobierna la forma en que las diferentes piezas se ubican y se relacionan entre sí. A la vista de ello, y de cara a un estudio del discurso político nobiliario, se plantea la cuestión de cómo manejar un material tan peculiar inserto en una obra tan problemática.

En primer lugar, ¿ hasta qué punto el texto refleja una elaboración por Fernán Sánchez de Valladolid o un material transmitido por éste? Pienso que la técnica del cronista - empezando por la propia decisión de incorporar el relato de la revuelta a su crónica - avala que lo que llega a nuestras manos es una versión razonablemente fiel del escripto en el que se basó. Sin duda, como ha demostrado González Jiménez, el cronista abrevió pasajes, introdujo algunas variaciones, e intentó amoldar el relato a su distorsionada cronología de los acontecimientos, entre otras cosas, por medio de la fragmentación del relato en capítulos; sin embargo, la complicada arquitectura que preside la inserción del relato es la mejor prueba de que era necesario «preparar el camino » para un texto que el cronista era perfectamente consciente de que contenía puntos ideológicamente sensibles. Las contradicciones de planteamiento entre este bloque y el resto de la crónica indican, igualmente, que Sánchez de Valladolid no alteró sistemáticamente y de manera sustancial el discurso de su fuente.

Aceptando esto, queda pendiente otra cuestión de gran calado : ¿ hasta qué punto podemos aceptar que un relato tan favorable al monarca transmite una imagen razonablemente ajustada de las alegaciones de los nobles y, por ende, de su discurso político? Aquí es necesario matizar. El anónimo autor tuvo indudablemente acceso directo a documentación 
perteneciente al conflicto de 1272-1273, de forma que pudo conocer con precisión las alegaciones y exigencias de los nobles y la forma en que éstas fueron argumentadas, al menos cuando lo fueron por escrito. Sin embargo, como indiqué más arriba, se puede descartar que el relato sea un encadenamiento de documentación copiada o extractada; es algo mucho más armado y complejo. Tampoco creo verosímil que, a pesar de que la cronología general de los acontecimientos - insertos de Sánchez de Valladolid aparte - sea válida, los encuentros concretos y los cruces de argumentaciones descritos sean fiel reflejo de hechos reales. El autor del escripto se valió, entre otros recursos expresivos, tanto de la reproducción - o invención - de fragmentos de estilo epistolar, como de la construcción de parlamentos en estilo directo, para dar mayor viveza a un conjunto que, en ocasiones, tiene más de diálogo polémico que de mera narración.

Dicho esto, otras razones mueven a pensar que el texto recoge, si no la expresión literal, sí al menos los fundamentos de las argumentaciones nobiliarias. Para el autor éste era un punto de la mayor importancia porque, de hecho, buena parte de las reivindicaciones de la década anterior se estaban repitiendo en sus días como argumentos de la revuelta acaudillada por el infante Sancho. En ese contexto el relato tenía un enorme potencial de propaganda política. Presentar un conflicto del pasado reciente en el que el monarca rebatía sistemáticamente las reivindicaciones desplegadas por los nobles era tanto como deslegitimar las aspiraciones de los sublevados del presente. Narrar cómo la obcecada rebeldía de los magnates se cerraba con su claudicación y vuelta a la obediencia era casi un acto de anticipación, que pretendía presagiar el fin del nuevo conflicto en una clave favorable al rey. En este sentido, el escripto que subyace a los capítulos XX-LVIII de la Crónica de Alfonso $X$ no es un mero ejercicio discursivo, es un instrumento de acción política tan real y potente como las maniobras diplomáticas y militares.

No es posible, por supuesto, pretender que la traslación de los argumentos nobiliarios hacia el relato se hiciese con fidelidad notarial, pero me inclino a pensar que los discursos cruzados en el texto entre rey y nobles se asemejan bastante a los que en su día pudieron enarbolar ambos contendientes. El estudio de Isabel Alfonso, en este mismo volumen, muestra de forma elocuente la coherencia interna de ambas posturas y, al mismo tiempo, su complejidad y riqueza de matices, lo que indica que no se trata de un discurso nobiliario standard, diseñado para recibir, como un punching-ball, los golpes de las refutaciones del monarca, sino que tras ello hay un denso despliegue de argumentaciones que operan a diferentes niveles de articulación política - desde reivindicaciones de tipo personal y patrimonial a argumentos de gran calado político - y apelando a una gama rica de registros discursivos. Por carecer del testi- 
monio directo, nos vemos obligados a formar nuestra imagen del discurso magnaticio a través de su representación por el autor del escripto. Este es un filtro que debemos tener siempre presente, pero, en conjunto, creo que el bloque formado por los capítulos XX-LVIII de la Crónica de Alfonso $X$ constituye un valioso material heurísitico, susceptible de ser utilizado para analizar el despliegue de argumentaciones puesto en marcha por los magnates en su conflicto con el monarca.

La dialéctica establecida en el texto entre el discurso regio y el nobiliario ha sido analizada por Isabel Alfonso, en este mismo volumen. Aquí voy a dejar relativamente aparte las contraargumentaciones regias y me centraré en las reivindicaciones de los nobles. El contraste entre sus argumentos y el contexto histórico permitirá apreciar no sólo qué clase de concepciones políticas hay tras ellos, sino también la relación entre argumentos esgrimidos y objetivos perseguidos, algo que hasta ahora apenas ha sido planteado en relación con este episodio.

\section{LOS ARGUMENTOS DEL DESGONTENTO NOBILIARIO}

No voy a hacer un análisis exhaustivo de todo el relato, tarea que desbordaría los límites de este trabajo. Por el contrario, me centraré en los primeros compases del conflicto - los inicios de la conjura magnaticia y la presentación de demandas al rey, primero en Lerma y luego en las Cortes de Burgos - porque es en estas etapas cuando se despliegan por extenso las razones de los nobles para alzarse contra su rey ${ }^{17}$. Las demandas de los nobles al rey - tal y como aparecen en los capítulos XX-LVIII de la Crónica de Alfonso $X$ - han sido sistematizadas por González Jiménez ${ }^{18}$. Sin embargo, es interesante apreciar que no todas ellas están presentes en todo momento. Junto con los motivos de carácter más personal, en los primeros compases - por ejemplo, en las cartas interceptadas del rey de Marruecos a los revoltosos (cap. XXII) - aparecen los siguientes :

- demandas tuertas (peticiones de servicios extraordinarios por el rey) ${ }^{19}$;

- monedas falsas y carestías (como consecuencia de la política regia de alteración en la ley de la moneda y tasación de precios);

- supresión del fuero antiguo en favor del Fuero real.

En las vistas celebradas en Burgos en septiembre de 1272 (cap. XXIII),

17. Para una sistematización más detallada de la mecánica del conflicto, tal y como se narra en los capítulos XX-LVIII de la Crónica de Alfonso $X$, me remito al trabajo de Isabel Alfonso, ya varias veces citado.

18. M. GONZÁLEZ JIMÉNEZ, Alfonso X, p. 97-98.

19. En esta sección las quejas sobre aspectos fiscales son poco precisas. Parecen centrarse en la cuestión de los servicios extraordinarios, que hay que suponer en relación con los preparativos del « fecho del Imperio », el cual sin embargo no aparece explícitamente mencionado. Sobre esta cuestión tendré que volver más adelante. 
las demandas y quejas presentadas al rey, y rebatidas por éste en el capítulo siguiente, fueron :

- que, a causa de los fueros dados por el rey a villas colindantes con las de los hidalgos, se apremiaba a éstos a implantar el mismo fuero;

- que no había en la Corte alcaldes de Castilla específicos que los juzgasen;

- que tanto el rey como los infantes, por medio de prohijamientos, obtenían heredades de particulares que otros nobles podían aspirar a recibir en herencia;

- que los servicios se recaudasen menos frecuentemente, y que no se demandasen por fuero;

- que se eximiese a los hidalgos del pago de la alcabala concejil de Burgos;

- que los merinos y cogedores del rey hacían muchos daños;

- que los nobles de Galicia y León se agraviaban por las pueblas que el rey hacía.

Días después, los nobles presentaron - ahora en Cortes - nuevas demandas (cap. XXv) :

- que hubiese en la Corte dos alcaldes hidalgos para juzgar los casos de hidalgos;

- que el rey deshiciese las pueblas que había mandado hacer en Castilla;

- que sustituyese en Castilla y León los merinos regios por adelanta$\operatorname{dos}^{20} ;$

- que retirase el impuesto del diezmo de los puertos, creado en 1268 ;

- que los vasallos de los hidalgos estuviesen exentos de servicios.

Además, en las mismas Cortes, un grupo de prelados - identificados todos ellos por Ballesteros como obispos del reino de León - presionó a su vez al rey con nuevas peticiones (cap. XXVI).

Antes de seguir adelante con el análisis, son pertinentes dos observaciones : por una parte, el grueso de las demandas tiene que ver con la preservación de los intereses patrimoniales y jurisdiccionales de los nobles; por otra parte, sólo en las cuestiones fiscales, y en parte en las jurisdiccionales, se aprecia una crítica de cierto calado hacia la política regia, argumentando que ésta puede suponer perjuicio para el reino. La « razón de Estado » que, en el capítulo XIX, Sánchez de Valladolid con-

20. Sobre esto ver M. GONZÁLEZ JIMÉNEZ, Crónica de Alfonso X, p. 87, n. 142. Para enjuiciar las cuestiones referentes a merinos y adelantados, es necesario tener en cuenta Cristina JULAR PÉREZ-ALFARO, Los Adelantados y Merinos Mayores de León (siglos XIII-XIV), Valladolid, 1990 y id., "Conflictos ante tenentes y merinos en los siglos XII-XIII ¿contestación al poder señorial o al poder regio? », Historia agraria, 13, 1997, p. 33-63. 
virtió en bandera del descontento de Nuño de Lara, está más que desdibujada en estas reivindicaciones, incluyendo, como era de esperar, el supuesto casus belli del tributo de Portugal.

En las páginas siguientes dejaré a un lado los argumentos de carácter más personal, en los que se discuten las quejas de determinados nobles que se sienten defraudados por el rey en sus aspiraciones patrimoniales o señoriales, porque esta cuestión está tratada con detalle en el trabajo de Isabel Alfonso. Mi aportación consistirá en estudiar los tres temas de mayor calado político - concretamente la cuestión de las pueblas, la cuestión del Fuero real y las demandas fiscales - con el fin de valorar la relación existente entre estas reivindicaciones y el desarrollo del conflicto en su contexto histórico concreto.

\section{Las Pueblas}

Alfonso X desarrolló una activa política de creación de pueblas a lo largo y ancho del reino. La lista de lugares de realengo que fueron creados o recibieron fuero bajo su reinado sería extensísima ${ }^{21}$. Sin embargo, es importante no olvidar dos aspectos :

Por una parte, la política de creación de pueblas no tenía nada de novedosa. Se había practicado de forma intensiva desde fines del siglo XI y había conocido un especial auge simultáneamente en León y Castilla en el período de separación de los reinos (1157-1230), demostrando con ello que se trataba de un movimiento general, independiente de un determinado rey o dinastía ${ }^{22}$. Como iniciativa específicamente atribuíble a Alfonso X, es posible que la combinación de las pueblas con la concesión del Fuero real en 1255 hubiese tenido un efecto particularmente explosivo en Castilla, pero, en todo caso, crear pueblas no era una novedad en absoluto, como tampoco lo era la oposición de los nobles a estas actuaciones, que se había manifestado con rotundidad en diversos momentos antes y durante el reinado de Alfonso $\mathrm{X}^{23}$.

Más importante es observar que en nuestro relato las quejas de los magnates no tienen por objetivo a todas las pueblas regias en general. En un primer momento (cap. XXIII) la queja parece circunscribirse a los reinos de León y Galicia, a los que se añade luego una petición análoga

21. Ver listados regionales y referencias básicas en M. GONZÁLEZ JIMÉNEZ, Crónica de Alfonso $X$, p. 82, n. 138 ; p. 84, n. 139 y p. 86, n. 141.

22. Sobre el notorio caso de Alfonso VIII de Castilla, ver su « Testamento político » de 1204 in : Julio GONZÁLEZ GONZÁLEZ, El reino de Castilla en la época de Alfonso VIII, Madrid, 1960, 3, p. 341-347 y el comentario de Pascual MARTÍNEZ SOPENA, « Réorganisation de l'espace et conflits de pouvoir: les pueblas reales au nord du Duero », in: Adeline RUCQUOI, Genèse médiévale de l'Espagne moderne. Du refus à la révolte : les résistances, Nice, 1991, p. 7-20.

23. P. MARTINEZ SOPENA, op. cit., p. 9-11. 
para el reino de Castilla en las vistas de Burgos (cap. XXV). De su formulación parece desprenderse que tanto León como Castilla deben ser aquí entendidos en sentido restringido, como los espacios al norte del río Duero, y que lo realmente irritante de la política regia era la creación de pueblas en los espacios intensamente señorializados al norte del río ${ }^{24}$. La razón es clara : no se trata tanto del hecho en sí de la fundación de una puebla regia como de su efecto sobre los intereses y la posición señorial de los nobles. El nuevo régimen jurídico de la localidad puede afectar, por una parte, a espacios circundantes de señorío laico o eclesiástico, derivando, bien en el drenaje de población hacia el realengo, bien en el surgimiento de peticiones de adecuar el régimen de los vasallos señoriales al de los del realengo; por otra, a las propiedades pertenecientes a nobles, pero englobadas dentro de los espacios jurisdiccionales (alfoces) de los nuevos concejos, donde la pugna se dará entre el pleno sometimiento jurisdiccional al concejo y la autonomía de las heredades y vasallos de los hidalgos.

Es importante subrayar la peculiaridad de las áreas al norte del Duero. Aquí, durante los siglos IX al XI, el proceso de emergencia de la clase feudal, en paralelo con las primeras etapas de maduración de la Monarquía, había descansado sobre una señorialización relativamente intensa, dando lugar incluso a la desarticulación de entidades territoriales supralocales que en otras circunstancias - por ejemplo, al sur del Duero sobrevivieron y a menudo cristalizaron como concejos urbanos de realengo ${ }^{25}$. Existen, como es lógico, variaciones comarcales, a veces muy fuertes dentro del espacio entre el Cantábrico y el Duero, sin embargo, y generalizando, se puede decir que a mediados del siglo XII un poblamiento fragmentado en aldeas relativamente autónomas, una intensa señorialización tanto laica como eclesiástica - particularmente monástica -, y un realengo relativamente desdibujado son los rasgos esenciales de esta región. En cambio, desde el siglo XI, la expansión territorial castellano-leonesa al sur del río había descansado, aunque con variaciones regionales, locales y cronólogicas, sobre el modelo hegemónico del concejo de realengo. En la mayor parte de estos espacios, la expansión territorial había consistido en la absorción o nueva creación de unidades ciudad-territorio que se integraban en el realengo, pero cuya dirección - especialmente la tenencia militar de sus fortalezas - era confiada a una

24. Un análisis detallado en P. MARTÍNEZ SOPENA, op. cit.

25. Sobre esto ver Julio ESCALONA MONGE, Transformaciones sociales y organización del espacio en el alfoz de Lara en la Alta Edad Media, Tesis doctoral, Madrid, 2000 (edición en CD-ROM, Universidad Complutense) y id., «Unidades teritoriales supralocales. Una propuesta sobre el origen del señorío de behetría », in : Carlos ESTEPA DÍEZ y Cristina JULAR PÉREZ-ALFARO (coord.), Los señorios de behetría, Madrid, en prensa. 
nobleza ya plenamente constituida y cuyas bases patrimoniales radicaban predominantemente al norte del Duero, por contraste con la debilidad relativa de su implantación dominical y señorial en las nuevas tierras $^{26}$.

Una consecuencia fundamental de estas variaciones en la estructura territorial fue que, desde fines del XI, y basándose en los modelos de poder que se estaban experimentando al sur del Duero y al otro lado de la Sierra central, los monarcas se afanaron por crear entidades jurisdiccionales y territoriales análogas a las extremaduranas en los espacios al norte del Duero, como elemento esencial de una política de potenciación del poder regio en ellos. Este es el origen de las pueblas regias, que se convirtieron en la punta de lanza de una tendencia a largo plazo hacia la recuperación del realengo ${ }^{27}$. El problema era que aquí, lejos de operar sobre un medio propicio, estas actuaciones se realizaban en contra de una situación consolidada de alta señorialización y, sobre todo, de un realengo muy fragmentado y cuyos límites con el señorío aristocrático estaban insuficientemente perfilados. Por más que las iniciativas regias y las protestas señoriales aparezcan bajo formulaciones generales sobre las pueblas, los fueros y el realengo, es obvio que la actitud de la nobleza hacia la política regia no podía ser ajena a unas estructuras territoriales y de poder tan diferentes : mientras que al sur del Duero las pueblas regias no sólo no planteaban ninguna amenaza para la nobleza sino que, a menudo, eran un vehículo eficaz para extender el poder nobiliario en unos espacios y comunidades donde aquélla carecía de implantación patrimonial, las actuaciones al norte del río entraban en clara contradicción con sus intereses, y lo hacían precisamente en las regiones donde radicaban sus bases patrimoniales y de clase. Pensamos que estas consideraciones ayudan a comprender el sesgo norteño perceptible en las reivindicaciones de 1272 .

Volviendo a nuestra fuente, el hecho de que la petición inicial fuese referida sólo a León y Galicia también encaja con el origen predominantemente leonés de los obispos que se enfrentan al rey ${ }^{28}$. Si posteriormente los nobles sublevados añadieron a esta demanda otra similar para Casti-

26. J. ESCALONA, «Unidades territoriales supralocales... »; para una discusión más detallada ver también, en su momento, Julio ESCALONA, « Señorío y tenencia en un período crítico. El enfrentamiento entre Alfonso VII y los Lara », trabajo presentado al Seminario Lucha política: condena y legitimación en las sociedades medievales, celebrado en la Casa de Velázquez (Madrid), los días 13-14 de diciembre de 2001, de próxima publicación.

27. José María MONSALVO ANTÓN, «Los territorios de las villas reales de la Vieja Castilla, ss XI-XIV : antecedentes génesis y evolución. (Estudio a partir de una docena de sistemas concejiles entre el Arlanza y el alto Ebro) », Studia historica. Historia medieval, 17, 1999, p. 15-86. 28. A. BALLESTEROS, op. cit., p. 585. 
lla, ello debe de responder a su estrategia de bloquear la negociación acumulando una montaña de quejas frente a la postura conciliadora del rey, deseoso de dar cuanto antes una salida pactada al problema. Y no porque en Castilla la cuestión de las pueblas fuese menos sensible, sino - a nuestro juicio - porque esta cuestión ya estaba presente implícitamente en sus reivindicaciones iniciales como una problemática particular centrada en la imposición del Fuero real.

\section{El Fuero real}

Casi desde los comienzos de su reinado - y probablemente siguiendo en esto pautas iniciadas bajo el reinado de su padre - Alfonso X puso en marcha un ambicioso programa de renovación legislativa orientado a imponer un marco jurídico global para el reino, centrado en la figura del monarca $^{29}$. Se trataba de un paso decisivo hacia la formalización estructural del entramado político-administrativo en la línea de favorecer una visión más « organizacional » o, si se quiere, más « corporativa » de la sociedad, con el monarca como cúspide de un edificio integrado por cuerpos funcionales al servicio del conjunto del reino. Huelga decir que una de las piezas clave de ese edificio era la redefinición de las relaciones entre el monarca y los poderes sociales, especialmente la nobleza o, - en términos corporativos - la caballería.

En el terreno práctico, la elaboración de instrumentos de tipo programático - el Espéculo y la primera versión de las Partidas - estuvo acompañada de la promulgación en 1255 del llamado Fuero real, que se suele ver como el primer intento práctico de superar la fragmentación jurídica del reino. Si esta medida fuese un esfuerzo general de centralización legislativa habría que ver las resistencias a la misma como una oposición frontal a la unificación jurídica en su conjunto; pero, de nuevo, la dimensión territorial permite situar la cuestión sobre un escenario diferente. Lejos de ser en origen un intento de unificar jurídicamente el reino entero, parece que la operación de 1255 estuvo destinada muy específicamente al territorio de la merindad mayor de Castilla, aunque luego se extendiese a otros lugares. De hecho, Gonzalo Martínez Díez ha demostrado que la mayoría de los manuscritos conservados del Fuero real, cuando no llevan destinatarios de tipo genérico, se dirigen a concejos del área castellana $^{30}$, y la misma idea viene avalada por otros testimonios independientes $^{31}$, entre ellos la propia Crónica de Alfonso $X$ (cap. IX) :

29. José Manuel PÉREZ-PRENDES, « Las leyes de Alfonso el Sabio », Revista de Occidente, 43, 1985, p. 67-84.

30. Gonzalo MARTÍNEZ DÍEZ, Leyes de Alfonso X, 2. Fuero Real. Edición y análisis crítico, Ávila, 1988, p. 107 sq., esp. p. 110.

31. Ibid. 
este rey don Alfonso, por saber todas las escripturas, fizolas tornar de latin en romançe. Et desto mando fazer el Fuero de las Leyes en que asono muy brevemente muchas leyes de los derechos. E diolo por ley e por fuero a la çibdat de Burgos e a otras çibdades e villas del reyno de Castilla, ca en el reyno de León avia el Fuero judgo que los godos ovieron fecho en Toledo. Et otrosy en las villas de las Estremaduras avian otros fueros apartados.

Sin ser estrictamente lo mismo, pensamos que hay una relación entre esta cuestión y la de las pueblas de León y Galicia. También Castilla era un espacio de arraigada implantación señorial, laica y eclesiástica, en comparación con las áreas al sur del Duero. Ahora bien, como estudios recientes no cesan de subrayar ${ }^{32}$, el panorama señorial era en la Castilla plenomedieval de una complejidad extrema, no sólo por la alta fragmentación de la propiedad y el señorío, sino también por la coexistencia de diferentes modalidades señoriales - abadengo, solariego, behetría, realengo - que la curia de Nájera (1185) ya había intentado regular, sin mucho éxito ${ }^{33}$. A pesar de que la tendencia histórica era el progresivo avance del señorío solariego como modalidad señorial típica de los laicos - hasta desembocar en el intento de conversión general de todas las behetrías en solariegos desestimado por las Cortes de Valladolid de $1351^{34}$-, a mediados del siglo XIII las bases de poder de la nobleza castellana estaban muy ligadas al señorío de behetría, que tenía un peso cuantitativo sustancial en muchos grandes patrimonios aristocráticos y, lo que es más, parece haber tenido una influencia notable en la articulación interna de las casas nobiliarias y en las estrategias de repartos sucesorios ${ }^{35}$.

Pero uno de los rasgos más llamativos del señorío de behetría es su alta conexión con el realengo, más evidente cuanto más se profundiza en sus etapas formativas ${ }^{36}$. A la altura de mediados del siglo XIII, el señorío de

32. Carlos ESTEPA DÍEZ, «Formación y consolidación del feudalismo en Castilla y León », in: En torno al feudalismo hispánico. I congreso de estudios medievales, León, 1989, p. 157-256; Ignacio ÁLVAREZ BORGE, Poder y relaciones sociales en Castilla en la Edad Media. Los territorios entre el Arlanzón y el Duero en los siglos x al XIV, 1996, Salamanca; Julio ESCALONA MONGE, «De "señores y campesinos" a "comunidades locales y poderes feudales". Elementos para definir la articulación entre territorio y clases sociales en la Alta Edad Media castellana », in : Ignacio ÁLVAREZ BORGE (coord.), Comunidades locales y poderes feudales en la Edad Media, Logroño, 2001, p. 117-155.

33. I. ÁLVAREZ BORGE, Poder y relaciones sociales..., p. 270 sq.

34. Carlos ESTEPA DIEZ, «Las behetrías en el canciller Don Pedro Lopez de Ayala », in: M. Isabel LORING GARCIA (ed.), Historia social, pensamiento historiográfico y Edad Media. Homenaje al prof. Abilio Barbero de Aguilera, Madrid, 1997, p. 95-114.

35. Ver el importante estudio de Ignacio ÁLVAREZ BORGE, « Nobleza y señoríos en Castilla la Vieja meridional a mediados del siglo XIV », Brocar, 21, 1998, p. 55-117. El conocimiento del señórío de behetría en Castilla ha avanzado mucho en los últimos años, gracias sobre todo a los trabajos de Carlos Estepa, pero falta por hacer una comparación exhaustiva entre Castilla y León.

36. Carlos ESTEPA DÍEZ, « Las behetrías y el poder regio », in : C. ESTEPA y C. JULAR 
behetría estaba teñido de ambigüedad, especialmente en el nivel del señorío singular : mientras un noble podía perfectamente entender sus behetrías como un espacio de poder aristocrático - bien que ciertamente limitado por un complejo y arcaizante derecho consuetudinario del que más de uno hubiera deseado desembarazarse -, desde la perspectiva del poder regio no era en absoluto irreal entender las behetrías como espacios de realengo, cedido a los señores en una fórmula que a los reyes cada vez les interesaba más presentar como equivalente a la tenencia. Aspectos cruciales, como la capacidad regia - $\dot{c}$ ancestral o en aumento en el siglo XIII? - para intervenir en la transmisión del señorío singular de las behetrías sólo tienen explicación por esta vía ${ }^{37}$.

Por otra parte, tampoco es necesario aplicar las categorías señoriales de forma rígida. El proceso de definición de los señoríos de behetría cubre un período de tiempo muy amplio y, aunque a la altura de comienzos del siglo XIII la behetría estaba ya configurada como categoría señorial, eso no quiere decir que estuviese igualmente resuelta la compleja cuestión de la asignación de una modalidad u otra a cada lugar concreto. Los estudios sobre el terreno más bien muestran una acusada indefinición y un grado de permeabilidad muy grande entre unas categorías y otras, a lo que no era ajena en absoluto la competencia entre las diferentes instancias señoriales por decantar en favor propio la configuración señorial de cada enclave ${ }^{38}$.

En la Castilla al norte del Duero amplias áreas señorializadas bajo la fórmula de la behetría coexistían con focos - generalmente muy fragmentados - de señorío más intenso - abadengo, solariego - y con una red de concejos de realengo de desarrollo territorial muy limitado en comparación con el sur, pero fuertemente apoyados por la monarquía como una pieza clave de su implantación regional ${ }^{39}$. Esta compleja combinación permite entender el impacto de la concesión del Fuero real en 1255. Más allá de su amplio articulado, el Fuero real debe ser visto, en esencia, como un intento de reformular la base legal del ejercicio del poder local a través del fortalecimiento del concejo realengo como maquinaria insti-

(coord.), Los señoríos de behetría, en prensa, y J. ESCALONA MONGE, « Unidades territoriales supralocales...».

37. Ver C. ESTEPA, « Las behetrías y el poder regio » y, sobre todo, su monumental estudio Las behetrías castellanas, de próxima publicación.

38. Para la comarca del alto Arlanza, he llamado la atención sobre la compleja situación creada por la frecuente coexistencia de solariego y abadengo, así como los numerosos ejemplos de transferencia entre realengo y abadengo de un poder señorial que parece muy semejante al señorío singular de las behetrías. Ver, próximamente, Julio ESCALONA MONGE, Sociedady territorio en la Alta Edad Media castellana. La formación del alfoz de Lara.

39. Ver J. M. MONSALVO, op. cit. 
tucional. El concejo se entiende aquí como un instrumento corporativo de base territorial directamente ligado a la Corona, con lo que en realidad tenemos un esfuerzo por fortalecer un señorío regio establecido por encima de una maquinaria de poder impersonal o formal, y ello dentro de un marco territorial y jurisdiccional relativamente mejor perfilado, en comparación con la articulación regional.

Dada la compleja situación de la Castilla al norte del Duero, el impacto de estas medidas pudo ser múltiple. En primera instancia, desde luego, apuntaba a los concejos de realengo, de los cuales Burgos era sin duda el más importante ${ }^{40}$. Pero, en un segundo nivel, en el éxito o el fracaso de la difusión del Fuero real en Castilla, también estaba en juego una potencial redefinición de las relaciones entre señorío del rey y señorío de los nobles en el seno de las behetrías, tendiendose a desequilibrar la balanza en favor del primero. De hecho, en la segunda mitad del siglo XIII fue aumentando el intervencionismo regio sobre las behetrías, particularmente sobre el señorío singular, una tendencia que continuó en la práctica, al margen de los desarrollos normativos.

Sería poco realista afirmar que el Fuero real servía de vehículo a un programa para la reconversión de las behetrías como realengos cedidos en tenencia a los señores laicos. Tal formulación era impensable en la segunda mitad del siglo XIII. Sin embargo, sí es claro que, en la sensible situación señorial de la Castilla al norte del Duero, una política de afirmación del señorío regio, por más que estuviese centrada primordialmente en los concejos de realengo que consideramos típicos, iba cargada con la potencialidad de servir como punto de partida para una afirmación más amplia del señorío regio en otros ámbitos donde la definición era mucho menor. Es el caso de las behetrías, pero también de una amplia nómina de lugares y comarcas donde el señorío del rey y el de los nobles laicos se entrecruzaba bajo fórmulas como los « realengos arcaicos », según el término acuñado por Carlos Estepa ${ }^{41}$. Recordemos que las categorías señoriales en sí estaban por entonces mejor perfiladas que el estatuto concreto de los lugares uno a uno, que sí podían ser sujetos de controversia.

No es extraño que los nobles fuesen reacios a aceptar estas medidas. Por una parte, y en relación con los realengos típicos, se planteaba un

40. No debe olvidarse que en 1255 se dan además pasos fundamentales en favor del concejo de Burgos, entre los cuales es especialmente llamativa la cesión al señorío concejil de algunas villas castellanas de gran importancia estratégica e histórica tanto para el rey como para la nobleza : Lara, Barbadillo del Mercado, Villafranca Montes de Oca, Villadiego y Belbimbre (Emiliano GONZÁLEZ DÍEZ, Colección diplomática del concejo de Burgos (884-1369), Burgos, 1984, doc. 130).

41. C. ESTEPA, « Las behetrías y el poder regio » y Las behetrías castellanas. 
claro punto de fricción en cuanto a si el principio de territorialidad se imponía sobre el criterio señorial, es decir, si el señorío concejil emanado del rey - pues de ello se trata - primaba en lo jurisdiccional sobre los vasallos de los hidalgos o éstos estaban exentos de la jurisdicción concejil en atención a su régimen señorial. Esta cuestión es de la mayor importancia, en términos de concepciones políticas. Pero, además, tenía la potencialidad de afectar a la consideración de los lugares de behetría ¿ debían éstos ser entendidos como lugares de señorío laico, si bien admitiendo una cierta superioridad regia - quizás un tanto subsidiaria expresada sobre todo en lo fiscal, o debían más bien ser tenidos por lugares de realengo cedido por el rey a un señor singular y sujeto, por tanto a revocación como las tenencias regias? Obviamente lo primero era más próximo al funcionamiento efectivo de las behetrías en ese momento, mientras que lo segundo, de llegar a imponerse, hubiera supuesto un extraordinario incremento de la capacidad regia para intervenir localmente en Castilla y para mediatizar a la nobleza castellana precisamente en la línea de flotación de sus intereses patrimoniales - cosa que, en todo caso, estaba ocurriendo en la práctica de forma creciente -, de ahí lo espinoso del asunto. No debe olvidarse que, a largo plazo, la memoria histórica que de este debate quedó en Castilla fue - si el preámbulo del Fuero viejo puede ser considerado como testimonio de ello - la de la concesión del Fuero real por el rey y su posterior retirada, precisamente en 1272, a ruegos de los nobles, en favor de la restauración de unos usos antiguos que son, en esencia y con todas las modificaciones incorporadas hasta 1356, un derecho de hidalgos y un derecho de behetría. El preámbulo del Fuero Viejo incide directamente sobre los acontecimientos que estamos analizando :

[...] el Rey don Alfonso [...] dio el fuero del libro a los concejos de Castilla que fue dado en [...] la era mil e doscientos e noventa e tres años, e judgaron por este libro fasta el sant Martin de Noviembre, que fue en la era de mil trescientos e diez años. E en este tiempo deste sant Martin los Ricos omes de la tierra e los Fijosdalgo pidieron merced al dicho Rey don alfonso que diese a Castiella los fueros que ovieron en tiempo del Rey don Alfonso su bisavuelo e del Rey don Fernando suo padre, porquellos e sus vasallos fuesen judgados por el fuero de ante si como solien : e el Rey otorgogelo, e mando a los de Burgos, que judgasen por el Fuero viejo ansi como solien $[\ldots]^{42}$.

42. IgnacioJORDÁN DE ASSO y Miguel DE MANUEL Y RODRÍGUEZ (ed.), El fuero viejo de Castilla : sacado, y comprobado con el exemplar de la misma obra, que existe en la real biblioteca de esta corte y con otros mss, Madrid, 1771, reimpr. Valladolid, 1983, preámbulo. La redacción sistemática del Fuero viejo data de 1356 (F. GÓMEZ REDONDO, op. cit., p. 297-300). El pasaje narra cómo en noviembre de 1272 los nobles castellanos « pidieron a Alfonso X por merced » que les concediese de nuevo sus fueros antiguos y éste se lo otorgó, en clara referencia a las Cortes de Burgos de ese año, pero pasa totalmente por alto que esta petición se diese en el contexto de la insurrección de la nobleza castellana, si bien la data del evento no deja lugar a dudas sobre ello. 


\section{Las cuestiones fiscales}

Hay, además, entre las demandas planteadas por los nobles, algunas cuestiones de carácter fiscal de indudable interés, aunque de muy variada naturaleza. Las quejas relativas a las alteraciones en la ley de la moneda son una de sus facetas ${ }^{43}$. Por otra parte, se da la exigencia general de que los servicios se recaudasen con menor frecuencia y que no se demandasen por fuero, es decir, que no adquiriesen el carácter de prestaciones ordinarias. Esta es una petición reiterada frecuentemente desde mucho antes ${ }^{44}$; por su formulación y por darse en el contexto de las Cortes de Burgos, así como por estar en flagrante contradicción con otras demandas de los nobles - como su exigencia del cobro de un servicio extraordinario para pagar sus soldadas -, pienso que, en este caso concreto, debe ser entendida como un intento por parte de los sublevados de concitar el apoyo de los concejos castellanos contra Alfonso X. Es más, si damos crédito a nuestra fuente - que en este punto destila indignación -, los ricoshombres eran perfectamente conscientes de que los servicios exigidos por el rey para satisfacer las soldadas tenían el doble efecto de beneficiarles económicamente al tiempo que hacían aumentar la oposición general contra el monarca (cap. XX). En un sentido parecido cabe considerar la queja contra los abusos cometidos por los merinos y cogedores del rey, aquí quizá con un guiño añadido hacia las instituciones eclesiásticas castellanas, que solían hacer de esta cuestión una de sus quejas más repetidas.

Más significativas, en cambio, son las exigencias de que los hidalgos estuviesen exentos de alcabala concejil en Burgos, o, sobre todo, de que los vasallos de los hidalgos estuviesen exentos del pago de servicios. Aunque se trate de asuntos fiscales, estas demandas cobran verdadero sentido al ser puestas en relación con otras discutidas más arriba, como dejar a los hidalgos y a sus heredades al margen de la jurisdicción de los concejos de realengo. Desde mi punto de vista, no se trata tanto de obtener beneficios económicos a corto plazo, ni de condenar la fiscalidad regia como tal, ni siquiera su mayor o menor voracidad, como de promover la idea de que ésta ha de ejercerse de forma general sobre el común, dejando al margen tanto a los nobles como a sus redes señoriales.

La materia fiscal está muy ligada a la construcción del Estado. Estas demandas nobiliarias no deben ser interpretadas de forma simplista, como expresión del tantas veces reiterado rechazo de la nobleza hacia el crecimiento de las estructuras estatales. Sobran, por el contrario, argu-

43. Sobre el interés de esta cuestión para la nobleza, ver Simon R. DOUBLEDAY, The Lara family. Crown and nobility in medieval Spain, Cambridge (Massachusetts), p. 70-71.

44. Ver, por ejemplo, una petición prácticamente en los mismos términos formulada por el Obispo y Cabildo de León en 1255 : José Mánuel RUIZ ASENCIO, Colección documental del Archivo de la catedral de León. VIII (1230-1269), León, 1993, doc. nº 2166. 
mentos para defender que el grado de dependencia de la nobleza respecto del aparato político de la monarquía era muy alto.

Por una parte, sus fundamentos como clase dominante en la sociedad feudal no pueden ser comprendidos sin un orden político que da forma y cobertura a los sistemas de propiedad y dominación que le sirven de base. También es en su seno donde se reproduce la legitimación ideológica y jurídica del status nobiliario y sus privilegios.

Por otra parte, en las etapas que estamos considerando, hacía ya largo tiempo que la renta feudal sensu stricto no bastaba a la nobleza para reproducir sus grandes redes clientelares, basadas en un sistema piramidal de circulación de servicios y redistribución de bienes. A la altura del siglo XIII - y de manera creciente en lo sucesivo - esto requería el acceso a recursos generados por el aparato de la Monarquía. La fórmula tradicional era, por supuesto, la prestación de servicios militares al monarca, que daba acceso a remuneraciones en bienes muebles, tierras, rentas, etc., de creciente peso en la alimentación de las redes de patronazgo. Esta dimensión militar no dejó de ser fundamental en todo el período, pero otras facetas fueron ganando peso a medida que crecía la formalización de la maquinaria estatal, y, sobre todo, su capacidad para generar recursos por vías diferentes a la renta feudal, a los que la nobleza, como clase dominante, tenía acceso preferente. La Monarquía desarrolló vías fiscales para establecer una detracción sistemática de excedente de carácter territorial, recurso que la nobleza por sí misma no podía generar, pero de cuya redistribución se beneficiaba en gran medida, bien directamente en forma de asignaciones o de soldadas para mantener sus tropas al servicio del rey, bien indirectamente, ya que el fisco alimentaba un sistema administrativo que la nobleza también instrumentalizaba.

$\mathrm{Y}$ no es una mera cuestión de obtener recursos económicos del Estado. De manera creciente, el desempeño de oficios regios - a veces difícil de distinguir de lo estrictamente militar - permitía acceder a mayores cotas de poder y a nuevos recursos, que podemos considerar de tipo « organizacional». A medida que la administración se iba complicando con la aparición de nuevas unidades y cargos, se desataba la lucha por ocupar los más altos cuadros de gobierno, que daban acceso no sólo a nuevos ingresos, sino también a controlar el acceso a los propios recursos generados por el Estado : caso de la práctica generalizada de delegar el ejercicio de oficios regios - tenencias sobre todo - entre los miembros de las redes clientelares de los magnates o, desde fines del siglo XIII, la lucha por la mayordomía regia en la medida en que ésta permitía controlar las asignaciones de soldadas ${ }^{45}$. 
La relación entre la nobleza y el aparato estatal, lejos de mostrarlos como términos antagónicos, muestra muchos rasgos de dependencia estructural de la primera respecto del segundo. Este es otro aspecto en el que resulta crucial considerar la desigual implantación nobiliaria en el territorio del reino, y de nuevo ello nos lleva a subrayar la peculiaridad de las áreas al norte del Duero. En efecto, es al norte del Duero donde la nobleza, tanto laica como eclesiástica, tenía sus bases de poder feudal, las que la convertían en clase dominante. En el resto del territorio su implantación era mucho más escasa. Por consiguiente, al sur del Duero y, sobre todo, al sur del Tajo, la mayor parte de la detracción de renta en favor de la nobleza se efectuaba por medio de los diversos mecanismos generados por la Monarquía aludidos más arriba. ¿Cabe aceptar la idea de una nobleza opuesta al crecimiento organizativo y fiscal de la Monarquía cuando éste era la base de su poder en la mayor parte del territorio? ¿ $\mathrm{O}$ es necesario aquilatar más y pensar que, aunque se formulen en términos generales, hay reivindicaciones que cobrar matices muy distintos según se esté pensando en el conjunto del reino o sólo en las tierras al norte del Duero?

\section{La dimensión territorial}

Llegados a este punto es posible plantear una idea del mayor interés. Si se repasan - como he hecho brevemente - las demandas de los nobles y su relación con las realidades sociales subyacentes, además de una política coyuntural de desobediencia al rey y de búsqueda de apoyos concretos, salta a la vista que la oposición nobiliaria a la Monarquía es menos contundente y frontal de lo que parecería en un principio. Varias de las cuestiones que los nobles identifican como sensibles y afectadas por la política regia, lejos de ser asuntos de política general a lo largo y ancho de la geografía del reino, tienen un claro contexto en las tierras al norte del río Duero, donde se concentraban los fundamentos socioeconómicos en que se basaba la nobleza castellana como clase feudal. En estas zonas las intervenciones regias cobran un sentido totalmente diferente. No hace falta forzar en absoluto el argumento para plantear que, cualquiera que fuese la actitud nobiliaria hacia el impacto de una política regia más o menos regalista sobre las tierras de reciente conquista, lo verdaderamente crítico era que esas mismas medidas afectasen al norte del Duero.

Esto permite también comprender que los nobles probablemente no tenían una postura homogéneamente opuesta al regalismo regio donde quiera que éste se manifestase, sino más bien la aspiración de que el ejer-

regios (Espéculo, lib. II; tit. XIII, ley II). Ver C. ESTEPA, Las behetrías castellanas, cap. 8. Agradezco en este aspecto los comentarios de Cristina Jular. 
cicio directo del poder regio se mantuviese al margen de sus propios señoríos. Y sería tremendamente simplista plantear esta toma de postura nobiliaria como mera expresión de unos mezquinos intereses de grupo, tendentes a salvaguardar sus patrimonios y las bases de su riqueza de los intentos fiscalizadores de la Monarquía. La cuestión tiene un calado mucho mayor. Pero antes es necesario profundizar un poco más en las circunstancias históricas de la insubordinación nobiliaria de 1272-1273.

\section{ESTREGHANDO EL GERO : EL GONTEXTO POLÍtiGo INMEDIATO}

Uno de los elementos más valiosos del texto analizado es que permite apreciar la impresionante montaña de argumentos, de índole tanto personal como general, que los nobles podían llegar a poner en pie para justificar su descontento con la política de Alfonso X. Esto no debe ser pasado por alto. En un momento en que el juego político de grandes bandos nobiliarios nucleados en torno a los principales ricoshombres empezaba a tomar carta de naturaleza en Castilla ${ }^{46}$, los dos principales linajes enfrentados - Lara y Haro - fueron capaces de dejar sus diferencias a un lado y unir sus esfuerzos en una operación tan arriesgada como impactante. Por encima de las aspiraciones personales a corto plazo de cada uno de los dirigentes, de las cuales son un magnífico exponente los cruces argumentales estudiados por Isabel Alfonso en su trabajo, esta convergencia fue en gran medida posible gracias a haberse construido un bloque compacto de reivindicaciones que, como se ha visto, tocaban directamente a los intereses de clase de la nobleza castellana en general, y en el cual todos ellos podían verse representados. En la práctica, estos argumentos demostraron ser capaces de unir y coordinar a un miembro de la familia real y a los tres ricoshombres más influyentes de Castilla, lo que no es poco. Una convergencia de este tipo es excepcional en un panorama donde dominan más bien los enfrentamientos sectoriales : uno de los bandos contra el rey, quien favorece a su vez a otro bando ${ }^{47}$. Esta excepcionalidad debe ser motivo de reflexión.

Como hemos visto, la insatisfacción nobiliaria enarbolaba algunas reivindicaciones que carecían de verdadera significación a escala de todo el reino, pero eran candentes al norte del Duero. Por otra parte, los tres linajes directamente implicados en la insubordinación, por más que sus intereses y sus relaciones, parentelares y políticas fueran muy amplios, eran esencialmente castellanos; y no sólo eso, juntos componían la quin-

46. C. ESTEPA, Las behetrías castellanas, cap. 8.

47. Ibid. De hecho, los mensajes de Alfonso X a los señores de Lara y Haro dejan meridianamente claro hasta qué punto este juego funcionaba de forma rutinaria y cómo todos los actores eran plenamente conscientes de ello. 
taesencia de la aristocracia castellana. Desde una perspectiva castellana se explican mejor muchos elementos de la revuelta, entre ellos la ulterior captación de apoyos secundarios, como algunos concejos y, sobre todo, del bloque de obispos leoneses que inesperadamente se enfrenta al rey en Burgos.

Pero, dando una vuelta de tuerca más, el estudio del relato cronístico revela una responsabilidad desigual entre los sublevados. Dejando a un lado al infante Felipe, relevante por su proximidad al rey - y por eso mismo muy útil a los sublevados -, todo apunta a un especial protagonismo de Nuño González de Lara : él es quien aparece en primer plano lanzando la conspiración y buscando los apoyos exteriores en Navarra ${ }^{48}$ y Granada. Las cartas dirigidas a Nuño González por Alfonso X son especialmente encendidas y están repletas de unos argumentos de carácter ético que apenas aparecen en el resto y que, de nuevo, delatan al Lara como auténtico « cerebro » de la sublevación. Todavía más : la topografía de la revuelta indica que ésta tuvo como escenario principal Lerma, el « punto fuerte » característico de los Lara en este período, por contraste con un Alfonso X que centra su poder en el concejo de realengo más importante de Castilla, Burgos, y que cuando ha de ir a Lerma encuentra un ambiente hostil (cap. XXIII).

Todo esto hace cambiar bastante el escenario. Tras esta revuelta general de la nobleza, como se ha repetido ¿ no podría esconderse una iniciativa más concreta del señor de Lara, a la sazón el ricohombre más poderoso del reino en ese momento, que habría sido lo bastante hábil como para movilizar al infante Felipe y a los Haro y Castro con un paquete de reivindicaciones que cualquiera de ellos estaría dispuesto a asumir?

Una de las razones más fuertes para pensar así es la ausencia de detonantes directos entre los argumentos de los sublevados. Repasando las exigencias más « politicas » de los nobles, llama la atención el hecho de que ninguna de ellas respondiese a actuaciones recientes por parte del rey : la política de pueblas era casi « tradicional », las exenciones fiscales, deseables pero no acuciantes, y, sobre todo, el rechazo al Fuero real, que parece ser uno de los puntos fuertes, podía ser intenso, pero ¿ por qué materializarse en ese preciso momento, diecisiete años después de su imposición? Puesto que ningún movimiento particularmente decisivo parece haberse producido en la cuestión foral inmediatamente antes de 1272, da la impresión de que un agravio de esta naturaleza podía perdurar larvado como un argumento de insatisfacción política y no movili-

48. Recuérdese la relación de los Lara con Navarra a través del entronque con los Azagra, que les permitió hacerse con el señorío de Albarracín (S. DOUBLEDAY, The Lara family..., p. 76). 
zarse - junto con otros argumentos paralelos - sino cuando se dieron las condiciones para una resistencia articulada. Lo mismo parece válido para las otras demandas, aunque algunas reivindicaciones, como las quejas de los Haro por la política regia de favorecer al infante Fernando en contra de sus expectativas sucesorias, podrían haber tenido mayor inmediatez en el tiempo y, de hecho, haber jugado su papel al favorecer la convergencia de los Haro con los Lara en un bloque unido, pese a sus diferencias.

Esta aparente ausencia de un detonante inmediato es tanto más expresiva cuanto que la revuelta se produjo en un momento crucial, y tuvo efectos políticos de larguísimo alcance ${ }^{49}$. En efecto, desde $c a$. 12701271 se desencadena la última fase del « Fecho del Imperio », un asunto que apenas aparece de refilón en la información transmitida por la Crónica de Alfonso $X$, pero que pudo influir en los acontecimientos mucho más de lo aparente a primera vista. Pese al triunfo de Ricardo de Cornualles en la elección de 1256, Alfonso X había mantenido sus aspiraciones imperiales, basadas sobre todo en el apoyo recibido de las comunas italianas. La muerte de Clemente IV, que dio paso a un interregno de tres años en el Papado, pudo reactivar las esperanzas del monarca, quien empezó a preparar la «ida al Imperio », es decir, presentarse en Lombardía y reivindicar desde allí el título imperial. Obviamente esto requería un nutrido ejército de apoyo, en lo cual la colaboración de los principales ricoshombres castellanos era esencial.

La coincidencia en el tiempo es muy relevante. A fines de 1271 fue elegido papa Gregorio IX, frontalmente opuesto a Alfonso, y la muerte de Ricardo de Cornualles en 1272 dio paso a la elección de Rodolfo de Habsburgo al año siguiente. Pero mientras esto sucedía, Alfonso X se afanaba en Castilla por solventar una inesperada e inoportuna revuelta nobiliaria «general», sin aparente detonante inmediato, y en la cual, pese a los esfuerzos del rey por contentar a los nobles, éstos fueron dilatando el problema hasta 1273. Cuando Alfonso X pudo contar en 1274 con la seguridad necesaria para realizar la « ida al Imperio », sus posibilidades reales - que, en cualquier caso, nunca fueron muchas - se habían esfumado, como su renuncia tras la entrevista con el papa en Beaucaire (1275) pronto confirmó. Es muy difícil entender la rapidez con que el rey - no sin argüir en su favor ${ }^{50}$ - cedió desde el principio a las principales reivindicaciones de los magnates, si no es porque tenía la perentoria

49. En esta argumentación debo agradecer muy especialmente los comentarios y sugerencias de Carlos Estepa.

50. I. ALFONSO, «Desheredamiento y desafuero... ». 
necesidad de conseguir su apoyo cuanto antes para poder aprovechar la oportunidad que se le presentaba de optar al Imperio.

Ahora bien ¿ puede ese contexto internacional ayudar a entender el alzamiento nobiliario? Desde luego, hay datos elocuentes, como el hecho de que la revuelta surja de manera tan inoportuna e inesperada para Alfonso X; que las quejas sean tan amplias y, al tiempo, tan « atemporales »; que, a pesar de las concesiones del rey, los nobles amontonen pretexto tras pretexto para desnaturarse y demorar una solución; y, desde luego, es relevante que, según la Crónica de Alfonso $X$, la primera medida del rey una vez conseguida la vuelta a la obediencia fuese obtener de los ricoshombres el apoyo militar deseado y organizar la tardía y fracasada « ida al Imperio » ${ }^{51}$. Hay, pues, un amplio margen para sospechar que la revuelta nobiliaria pudo tener un objetivo diferente, inmediato y concreto : estorbar los planes imperiales de Alfonso X. Para ello no valía un conflicto pequeño. Era necesaria la oposición de una parte esencial de la alta nobleza, por encima de divisiones de bandos. Y para esto se requería a su vez una unidad de intereses que es muy clara en las reivindicaciones « de clase » planteadas.

Si admitimos que el diseño de la insurrección puede apuntar a una maniobra de Nuño González de Lara, la cuestión cobra matices diferentes. Nuño González era cabeza del más importante linaje nobiliario castellano y, por ende, del bando más poderoso ${ }^{52}$. Sus amplísimos intereses alcanzaban León, Portugal, Aragón, Navarra y Francia, pero sobre todo, los Lara eran el grupo magnaticio dominante en Castilla, una posición generada en el siglo XII y mantenida en adelante, primero frente a los Castro y luego frente a los Haro ${ }^{53}$. Tras un período de relativo retroceso como consecuencia de la oposición de los Lara a Fernando III, Alfonso X, ya desde sus tiempos de infante, había favorecido a Nuño González y le había ayudado a revivir la antigua pujanza. Sin embargo,

51. Aunque esto es bastante especulativo, me pregunto si la cuestión de la ida al Imperio no pudo desempeñar un papel más explícito en los sucesos de 1272-1273, y quedar minimizada en el relato construido una década después porque la aventura imperial había dejado de ser ya un tema políticamente candente.

52. Para una documentada visión de conjunto sobre la trayectoria de los Lara en los siglos XII y XIII debe consultarse S. DOUBLEDAY, The Lara family... Sin embargo, en relación con las bases patrimoniales de su poder, y sus relaciones con el poder regio, es preciso tener en cuenta las observaciones de C. ESTEPA, Las behetrías castellanas y J. ESCALONA, « Señorío y tenencia... ». Sobre las alineaciones nobiliarias en los inicios del reinado de Alfonso X, ver Ana RODRÍGUEZ LÓPEZ, "Rico fincas de tierra et de muchos buenos vasallos, mas que rey que en la Cristiandat sea. La herencia regia de Alfonso X », Cahiers de linguistique hispanique médiévale, 23, 2000, p. 243-261.

53. En general, sobre la nobleza castellana del siglo XII, ver Simon BARTON, The aristocracy in twelfth-century León and Castile, Cambridge, 1997; en concreto sobre los Lara, S. DOUBLEDAY, The Lara family... Para la evolución estructural a tiempo largo de la nobleza castellana plenomedieval, la referencia esencial debe ser, sin embargo, C. ESTEPA, Las behetrías castellanas. 
la relación entre el rey y Nuño González, que había sido estrecha en los años finales de Fernando III y en los primeros años de reinado de Alfonso, se fue enfriando hasta un punto próximo a la ruptura a la altura de $1270^{54}$. En ese año Juan Núñez de Lara, hijo de Nuño González, y también muy próximo al rey y al infante Fernando ${ }^{55}$, había partido del reino, seguramente contra la voluntad de Alfonso X, para tomar parte en la Gruzada contra Túnez en calidad de vasallo del rey de Navarra - enemigo del monarca castellano -, con quien tenía lazos como señor de Albarracín. Esto sin duda tuvo que contrariar a Alfonso y es posible que actuase contra él, a juzgar por algunas alusiones que se deslizan en la Crónica ${ }^{56}$. Al alejamiento entre el magnate y el rey se unía una ya larga tradición de relaciones ultrapirenaicas de $\operatorname{los}$ Lara $^{57}$. ¿ No tendría pleno sentido pensar que la convergencia de intereses entre el señor de Lara y el rey de Francia en el especialísimo contexto de 1270-1271 pudo ser determinante en el estallido de una revuelta tan peculiar, y justo en ese momento? Carecemos de evidencias contundentes en esta dirección, pero es una posibilidad que convendría sondear más a fondo.

\section{Apuntes, más Que Gonclusiones : Algunas sugerenGias SOBRE EL PENSAMIENTO POLÍTICO DE LA NOBLEZA GASTELLANA EN EL SIGLO XIII}

1. Como se ha podido ver, el análisis de las demandas de los nobles en el conflicto de 1272-1273, en contraste con las realidades a las que hacen referencia, me ha llevado por un camino de lo general a lo particular. Los

54. S. DOUBLEDAY, The Lara family..., p. 69 sq. Según la Crónica de Jaime I, el preludio habría estado, a fines del año anterior, en un encuentro entre Nuño González y el rey aragonés, en el que el primero habría ofrecido pasar al servicio del segundo, lo que este habría rechazado. Si hemos de dar crédito a este relato, aquí tendríamos ua aproximación del señor de Lara hacia posiciones de rebledía mucho más verosímil que la retratada en la Crónica de Alfonso X, y con el valor adicional de retrasar en más de dos años la animosidad de Nuño González contra al rey. Ver Ferrán SOLDEVILA (ed.), Les quatre grans cròniques, Barcelona, 1983, p. 172. S. DOUBLEDAY discute este pasaje y su relación con la convergencia entre Nuño González y el monarca francés (The Lara family..., p. 78 y n. 119).

55. Esto es particularmente evidente en los términos en que el rey le reprocha su defección; ver I. ALFONSO, « Desheredamiento y desafuero... », en este mismo volumen.

56. Cap. XXX.

57. Ana RODRÍGUEZ LOPEZ, «Quod alienus regnet et heredes expellatur. L'offre du trône de Castille au roi Louis VIII de France », Le Moyen Age, 105, 1999, p. 109-128. Las vinculaciones se hacen más evidentes tras la muerte de Fernando de la Cerda en 1275. El triunfo de Sancho IV puede ser perfectamente visto en su dimensión de ascenso de un bando anti-Lara comandado por los Haro (C. ESTEPA, Las behetrías castellanas, cap. 8) y tuvo como elocuente consecuencia la salida de Juan Núñez del reino y su paso a Francia como vasallo del rey Felipe III en 1276, lo que también ayudó a mantener el apoyo capeto hacia los herederos de Fernando de la Cerda. Por otra parte, sobre la vinculación de los Lara con la familia real aragonesa, ver S. DOUBLEDAY, The Lara family..., p. 77-78. 
argumentos del descontento nobiliario, tal y como se reflejan en el texto estudiado, no sólo apuntan a cuestiones de carácter personal y coyuntural; también ponen en pie aspectos gran calado político, que afectaban a las líneas de actuación desarrolladas por la Monarquía en los años anteriores. Pero un análisis en profundidad revela que estos argumentos cobran un valor especial en el contexto de los territorios al norte del Duero y, especialmente, del ámbito castellano. Dando un paso más, la mecánica de la insubordinación parece señalar especialmente a Nuño González de Lara como principal arquitecto del conflicto. Finalmente, el impacto en el contexto político internacional, así como las propias conexiones exteriores del señor de Lara, sugieren con fuerza que la insubordinación pudo ser un conflicto « de diseño » destinado a obstaculizar los planes imperiales de Alfonso X. Se trata, al mismo tiempo, de una conclusión y de una hipótesis que necesita ser desarrollada con mayor extensión que la que permiten estas páginas.

Ahora bien, si los argumentos de nuestro texto han de ser entendidos más como pretextos que como motivaciones, ¿ en qué medida afecta eso a mi planteamiento inicial? Por más que el momento y el ritmo pudieron haber estado marcados directamente por la evolución del contexto político peninsular y extrapeninsular, el hecho de que entre los sublevados hubiera una « agenda oculta » no quiere decir, en mi opinión, que las reivindicaciones nobiliarias estuviesen vacías de contenido. Las mejores pruebas de ello son, por una parte, que sirvieron para componer un frente relativamente monolítico por encima de rivalidades de bando; y por la otra, que, de hecho, permitieron a los ricoshombres arrancar al rey algunas concesiones muy apetecidas. Y ahí reside su valor; aunque los objetivos últimos de Nuño González de Lara pudieron ser otros, el « paquete » de demandas puesto sobre la mesa por los nobles cumplió con su misión - sobre todo en lo referente a aglutinar un frente nobiliario cohesionado - porque tenían sentido como expresión de las aspiraciones de los ricoshombres castellanos. En todo caso, el éxito estratégico de sus demandas viene a subrayar cómo el discurso político puesto en juego es una herramienta fundamental - y con un apreciable grado de autonomía - de la acción política práctica.

2. Dicho ésto, ¿ en qué medida la discusión de este material permite avanzar algo en el conocimiento del pensamiento político de los nobles castellanos del siglo XIII? Las posibilidades de indagar este aspecto antes de la baja Edad Media vienen lastradas por toda una historiografía tradicional que ha tendido, teleológicamente, a alinearse las posturas de una monarquía a largo plazo triunfamente. Al hacerlo, tendía a conformar un retrato de la nobleza como disolvente o particularista, y su acción política 
como puro egoísmo individualista, como una sistemática canibalización de los recursos del Estado con fines de incrementar la riqueza y el poder de sus miembros.

La cuestión es otra, por supuesto, y mucho más compleja. A la altura del último cuarto del siglo XIII, la reproducción de la dominación nobiliaria dependía en gran medida del aparato del Estado. El crecimiento de un aparato estatal más formalizado y centralizado no sólo no iba en detrimento de la clase nobiliaria, sino que, bien al contrario, era una herramienta fundamental de crecimiento político que la nobleza, de hecho, instrumentalizaba habitualmente. ¿Dónde está, pues, la raíz del enfrentamiento entre los nobles y el rey? No hay que olvidar que, por más que los móviles de la insubordinación de 1272-1273 fuesen en gran parte estratégicos, lo que aglutinó a los nobles contra su monarca fue un paquete de demandas que hoy denominaríamos « de consenso », capaz de superar las rivalidades internas de los ricoshombres. Unas demandas de este tipo pueden en gran medida ser consideradas retazos de algo próximo a un « programa político ». Lógicamente, no es posible resolver una cuestión tan densa sólo a partir del material textual que analizo aquí, pero dos ideas parecen surgir con cierta claridad :

a) En primer lugar, la consideración de la dimensión territorial - un aspecto habitualmente dejado de lado por las aproximaciones a estos temas - revela que las iniciativas regias eran percibidas de manera diferente al norte del Duero, donde la nobleza era fuerte como clase feudal, y en el resto, donde una parte importante de su poder se generaba y se ejercía por intermediación de un aparato estatal de control y detracción de renta.

b) En segundo lugar, y por esta misma razón, los argumentos de queja de los nobles pueden ser entendidos, no tanto como rechazo frontal a una política « regalista », sino más bien como rechazo de aquéllos aspectos de la política regia que vulneran los fundamentos de clase de la nobleza feudal. Y esta vulneración tiene una inequívoca dimensión territorial ${ }^{58}$.

Las demandas de los nobles frente a Alfonso X no expresan necesariamente su oposición al crecimiento del Estado y a la centralización de poder. Pueden muy bien ser reflejo de la discrepancia de los ricoshombres sobre el «modelo social » que se propugna desde la monarquía y, sobre todo, sobre el papel de la nobleza en el seno del mismo. Las iniciativas promovidas por Alfonso X tendían a «formalizar» al estamento nobiliario como un «cuerpo de caballería » al servicio de la Corona, remunerado por ésta en retribución por su servicio; una funcionariza- 
ción no ocasional, sino radical de la nobleza en su conjunto, al margen de los aspectos patrimoniales. Otras actuaciones, como la promulgación del Fuero real, indican que la tendencia era la reformulación del poder estatal sobre bases eminentemente territoriales. Se impulsaba el control del poder y la jurisdicción a nivel local por medio de entidades espaciales (concejos, merindades, adelantamientos) de titularidad regia, concebidas con capacidad para englobar a la totalidad de la población, incluyendo a los vasallos de los nobles habitantes en el seno de las mismas. Esto en el sur recién conquistado podía ser un tema de poco debate, pero en el norte, donde el tradicionalmente escaso señorío de realengo venía incrementándose sistemáticamente desde hacía casi dos siglos, y donde el señorío de behetría - base de la estructuración de poder de la nobleza contenía elementos muy sensibles a un potencial incremento de sus dimensiones como realengo, la cuestión era muy diferente.

Es fácil pensar que las aspiraciones de la nobleza en cuanto a la exención fiscal y jurisdiccional de sus vasallos sólo encierra un deseo de obtener ventajas relativas en competencia con los concejos. Sin embargo, en la línea que propongo, más bien sugieren que los ricoshombres podrían estar buscando promover un modelo social que, sin rechazar de plano la « corporativización funcional »-que, de hecho, tenía muchas ventajas promovía la consideración de la nobleza en un plano de superioridad - estamental, si se quiere - de marcado carácter extraterritorial, que tendía a situar la totalidad de sus bases de poder al margen de las iniciativas de control regio de naturaleza territorial, fundamentalmente los concejos. En este sentido apuntan peticiones como la emancipación de los vasallos de los nobles respecto de la jurisdicción concejil, o su exención de servicios regios, o el deseo de tener alcaldes propios en la Corte.

Lógicamente estos temas debían formularse en los términos más generales que fuese posible, pero en la práctica, una propuesta de este tipo entrañaría la peculiar contradicción de pretender hacer del espacio al norte del Duero un gran coto cerrado nobiliario, frente al resto del territorio, donde el poder regio no sólo era mejor recibido, sino, la herramienta indispensable para la dominación nobiliaria.

El éxito de estos argumentos a la hora de articular la insubordinación de 1272-1273 así como su rebrote en la década siguiente en la revuelta de Sancho IV son los mejores indicadores de que tras de ellas había, si no un programa, sí al menos un amplio consenso nobiliario en torno a un modelo de sociedad y a la posición de la nobleza en el mismo. Lógicamente antes del siglo XIV sólo raramente podemos acceder a muestras de un pensamiento político nobiliario expresado « en positivo », frente a los retratos « en negativo » con que nos obsequia la maquinaria escrituraria 
regia. La sección analizada de la Crónica de Alfonso $X$ contiene algunos retazos de esta cultura política de los ricoshombres. Mi análisis ha consistido en dejar de lado el recurso fácil de asumir directamente el discurso regio o condenar de antemano a los nobles como facinerosos posibilistas, y sugerir que probablemente estamos ante dos maneras alternativas de entender el crecimiento del aparato estatal y la formalización de modelos sociales más orgánicos y centralizados.

$\mathrm{Si}$, en último término, las propuestas de la Monarquía entran en conflicto con las de los nobles, a pesar del enorme y reconocido peso de los valores y la ideología caballeresca en la propia formulación de los modelos alfonsinos, quizá sería necesario volver la cuestión del revés y preguntarnos qué elementos son los que impiden que la formulación política de la monarquía sea casi mimética con las posturas de la nobleza y qué fuerzas sociales subyacen a un modelo centralizador no sólo en lo legal sino también en lo territorial. Los nobles castellanos del siglo XIII podían, sin duda, tener un pensamiento político propio, pero ¿quién pensaba el pensamiento de la Monarquía? 